\title{
CVD transfer-free graphene for sensing applications
}

\author{
Chiara Schiattarella ${ }^{1}$, Sten Vollebregt ${ }^{2}$, Tiziana Polichetti ${ }^{*}{ }^{3}$ Brigida Alfano $^{3}$, \\ Ettore Massera ${ }^{3}$, Maria Lucia Miglietta ${ }^{3}$, Girolamo Di Francia ${ }^{3}$ \\ and Pasqualina Maria Sarro ${ }^{2}$
}

\author{
Full Research Paper \\ Address: \\ ${ }^{1}$ University of Naples "Federico II", Department of Physics "E. \\ Pancini”, Naples, Italy, ${ }^{2}$ Delft University of Technology, Department of \\ Microelectronics, Delft, The Netherlands and ${ }^{3} E N E A$ C.R. Piazzale \\ Enrico Fermi, 1, 80055 Portici (Naples), Italy \\ Email: \\ Tiziana Polichetti* - tiziana.polichetti@enea.it \\ * Corresponding author \\ Keywords: \\ ammonia; chemiresistors; CMOS-compatible process; graphene; \\ nitrogen dioxide; transfer-free growth
}

Beilstein J. Nanotechnol. 2017, 8, 1015-1022.
doi:10.3762/bjnano.8.102

Received: 29 July 2016

Accepted: 18 April 2017

Published: 08 May 2017

This article is part of the Thematic Series "Functional materials for environmental sensors and energy systems".

Guest Editor: M. Penza

(C) 2017 Schiattarella et al.; licensee Beilstein-Institut. License and terms: see end of document.

\begin{abstract}
The $\mathrm{sp}^{2}$ carbon-based allotropes have been extensively exploited for the realization of gas sensors in the recent years because of their high conductivity and large specific surface area. A study on graphene that was synthetized by means of a novel transfer-free fabrication approach and is employed as sensing material is herein presented. Multilayer graphene was deposited by chemical vapour deposition (CVD) mediated by CMOS-compatible Mo. The utilized technique takes advantage of the absence of damage or contamination of the synthesized graphene, because there is no need for the transfer onto a substrate. Moreover, a proper pre-patterning of the Mo catalyst allows one to obtain graphene films with different shapes and dimensions. The sensing properties of the material have been investigated by exposing the devices to $\mathrm{NO}_{2}, \mathrm{NH}_{3}$ and $\mathrm{CO}$, which have been selected because they are wellknown hazardous substances. The concentration ranges have been chosen according to the conventional monitoring of these gases. The measurements have been carried out in humid $\mathrm{N}_{2}$ environment, setting the flow rate at $500 \mathrm{sccm}$, the temperature at $25^{\circ} \mathrm{C}$ and the relative humidity $(\mathrm{RH})$ at $50 \%$. An increase of the conductance response has been recorded upon exposure towards $\mathrm{NO}_{2}$, whereas a decrease of the signal has been detected towards $\mathrm{NH}_{3}$. The material appears totally insensitive towards $\mathrm{CO}$. Finally, the sensing selectivity has been proven by evaluating and comparing the degree of adsorption and the interaction energies for $\mathrm{NO}_{2}$ and $\mathrm{NH}_{3}$ on graphene. The direct-growth approach for the synthesis of graphene opens a promising path towards diverse applicative scenarios, including the straightforward integration in electronic devices.
\end{abstract}

\section{Introduction}

Due to its extraordinary electronic, chemical, mechanical, thermal and optical properties, graphene has been defined as the "wonder material" of the 21 st century with plentiful applica- tions in several fields such as energy storage, biomedical, electronics [1]. Among these applications, one of the most promising is likely that in the field of gas sensors, where the main 
requirements, namely high specific surface-to-volume ratio, high mobility and low electrical noise, are all precisely concentrated in this material. As it has been reported by Varghese et al. in a recent review on chemical sensors, the interest of the scientific community towards graphene for sensing applications is continuously growing, as testified by the increasing number of publications dedicated to graphene-based sensors [2]. The gas sensor devices presented in literature are mostly based on pristine graphene, graphene oxide (GO) and reduced graphene oxide (rGO). Many approaches for the fabrication of such materials, including CVD, mechanical, chemical and electrochemical exfoliation can be employed. Each provides a sensing layer with a pronounced specificity towards a particular analyte [3-6] However, the issue of selectivity is far away from being solved. A possible solution could be represented by resorting to the design of an array of sensors that can discriminate between analytes by comparing and analysing responses from multiple devices [7].

Another issue that needs to be addressed is the problem of slow and incomplete recovery in the operative regime of standard temperature and pressure, which can be solved by providing the sensors with appropriate electronics, able to perform data analysis [8] or a refresh of the device through UV illumination or thermal annealing [9-13].

All that said, the development of new approaches enabling the direct growth of large-area graphene layers on arbitrary insulating substrates, compatible with conventional Si technology, is of crucial importance $[14,15]$. A possible choice for the synthesis of large-area graphene is the metal-assisted hydrocarbon dissociation and/or the deposition method from solid carbon sources. In both cases, after the growth the graphene film needs to be transferred onto other substrates for the fabrication of devices [16-19]. A step forward in the direction of the transferfree synthesis has been made by Kwak et al. [20] who proposed a diffusion-assisted synthesis method for uniform and controllable deposition of graphene films with micrometre-sized grains at a $\mathrm{Ni} / \mathrm{SiO}_{2}$ interface. More recently, Lukosius et al. have shown the successful growth of a graphene layer underneath $\mathrm{Ni}$ bars on insulating $\mathrm{SiO}_{2}$ layers, so avoiding the metal contamination problems and complexity associated to graphene transfer [21].

In the present work, we show the results of the sensing performances of conductometric devices in which multilayer graphene films have been directly synthesized on insulating $\mathrm{SiO}_{2}$ substrates by means of a transfer-free CVD method mediated by Mo. The pre-patterning of the Mo layer allows the graphene to be shaped in the desired form by means of standard lithography techniques, following a completely Si-technology- compatible approach. Chemiresistive devices have been realized by shaping the sensing layer in form of rectangular strips.

In order to probe the gas-sensing capabilities of the fabricated devices, three standard pollutants have been chosen, namely $\mathrm{NO}_{2}, \mathrm{NH}_{3}$ and $\mathrm{CO}$. In particular, $\mathrm{NO}_{2}$ and $\mathrm{NH}_{3}$ are known to exhibit an electron acceptor- and donor-like nature respectively, as extensively shown in the literature $[13,22,23]$. The chosen concentration ranges are the same than those monitored in conventional contexts.

Finally, the sensing specificity of the material has been probed by evaluating and comparing the degree of adsorption and the interaction energies for $\mathrm{NO}_{2}$ and $\mathrm{NH}_{3}$.

\section{Results and Discussion Materials characterization}

The material, prepared according to the procedure discussed in detail in the Experimental section, has been morphologically and structurally characterized in a previous work [24], from which it emerged that the average number of layers was about 20. The material showed to be free from metal impurities after Mo removal and not damaged by the lift-off process. The quality of the graphene film has been monitored via Raman spectroscopy throughout the whole fabrication process: after CVD growth, after Mo etching and after lift-off. The absence of contamination has then been attested by EDX analysis.

In Figure 1 a representative optical micrograph of the fabricated devices is reported. The graphene layer (dark strip highlighted in red) and gold contacts with wire-bonds are clearly visible. As can be seen, accurately defined multilayer graphene

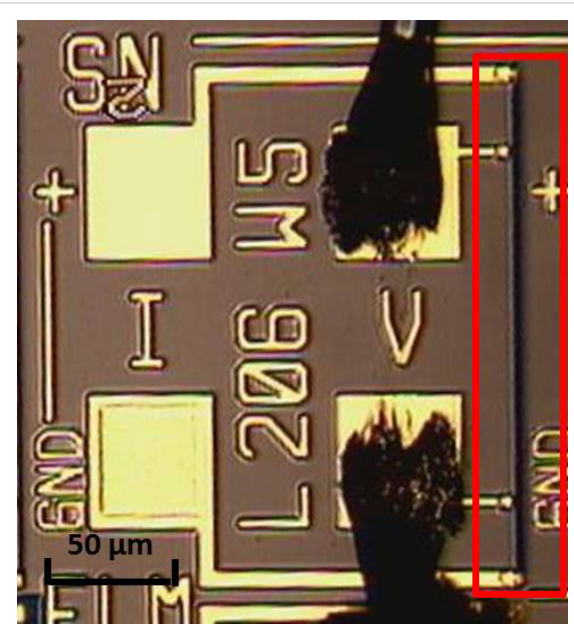

Figure 1: Optical micrograph of one of the CVD graphene-based chemiresistive devices. The graphene strip is highlighted in red. The length / and width $w$ of the sensing strip (in $\mu \mathrm{m}$ ) have also been indicated and patterned between the electrodes. 
patterns down to micrometre-size can be obtained using this method. From an electrical point of view, the fabrication technique has proven to be quite repeatable and uniform, since devices with the same geometry either coming from different wafers or within the same one had the same base resistance. Furthermore, the graphene exhibited a p-type electrical characteristic.

Starting from this premise, we have further deepened the analysis of the material by performing a Raman analysis in several different sites of the graphene film. As can be seen in Figure 2, the spectra display a fair uniformity. In particular, the arising of the $\mathrm{D}\left(\mathrm{ca} .1350 \mathrm{~cm}^{-1}\right.$ ) and $\mathrm{D}^{\prime}$ (ca. $1600 \mathrm{~cm}^{-1}$ ) bands is related to presence of defects and in particular the $\mathrm{D}$ intensity, roughly 5-fold lower than that of the G peak, attests a low density of defects. This evidence confirms the non-degradation of the material even during ageing.

The analysis of the $I(\mathrm{D}) / I\left(\mathrm{D}^{\prime}\right)$ ratio allows one to discriminate the type of defects in the film. Indeed, as reported by Eckmann et al., the value of the slope of the $I(\mathrm{D}) / I(\mathrm{G})$ vs $I\left(\mathrm{D}^{\prime}\right) / I(\mathrm{G})$ curve, namely $I(\mathrm{D}) / I\left(\mathrm{D}^{\prime}\right)$, can be related to the preponderant typology of defects in the different graphene samples [25]. In particular, the $I(\mathrm{D}) / I\left(\mathrm{D}^{\prime}\right)$ ratio exhibits its maximum value, around 13 , for $\mathrm{sp}^{3}$-like defects, it decreases down to about 7 in the case of vacancies and it is minimum for edge defects (ca. 3.5). In our case the estimated $I(\mathrm{D}) / I\left(\mathrm{D}^{\prime}\right)$ value is around 4.4 , indicating that defects in the material are reasonably ascribed to the boundaries.

\section{Gas-sensing study}

In order to investigate the reliability of the fabrication process in terms of gas-sensing behaviour, two identical devices have been considered, labelled with A and B. As described below in the Experimental section, the sensing layer has a rectangular geometry: $l=206 \mu \mathrm{m}, w=5 \mu \mathrm{m}$ (Figure 1) and $t=7.2 \mathrm{~nm}$. The two devices have been tested towards $1 \mathrm{ppm}$ of $\mathrm{NO}_{2}, 250 \mathrm{ppm}$ of $\mathrm{NH}_{3}$ and $10 \mathrm{ppm}$ of $\mathrm{CO}$ in $\mathrm{N}_{2}$ atmosphere. An inert carrier gas rather than a more realistic environment (i.e., by employing synthetic air) was chosen because of the undesired influence of oxygen. The number of active sites on the graphene surface decreases due to binding of $\mathrm{O}_{2}$ molecules via weak physisorption [26]. This phenomenon tends to impair the quantitative study that will be carried out afterwards, leading to an underestimation of the amount of adsorbable analyte. However, it is important to underline that oxygen does neither actively and crucially affect the physics of the sensing process nor the performance of the devices, which is only worsened to a little extent.

Figure 3 displays the dynamic response of the conductance of the devices towards $1 \mathrm{ppm}$ of $\mathrm{NO}_{2}$. As can be observed, the base conductance values are comparable $\left(G_{\mathrm{A}} \approx G_{\mathrm{B}} \approx 22 \mu \mathrm{S}\right)$. During exposure, both chemiresistors exhibit an identical percentage variation of the conductance without reaching a plateau. In the figures the asymptotic values of conductance are also displayed. Such quantities have been evaluated by extrapolating the final conductance value by fitting each curve, within the time window of exposure to the analyte, with the exponential function

$$
G(t)=G_{\mathrm{MIN} / \mathrm{MAX}}+\left(G_{0}-G_{\mathrm{MIN} / \mathrm{MAX}}\right) \exp \left(-\frac{t}{\tau}\right)
$$

where $G_{\text {MIN/MAX }}$ represents the asymptotic value of the conductance after exposure to the analyte. When the gas inlet is stopped, a slow decrease of the device conductance and thus an incomplete recovery follows. This is not surprising and can be explained in terms of interaction energy between graphene and analyte, as will be explained later. Since $\mathrm{NO}_{2}$ acts as an electron acceptor, during interaction the electronic charge is transferred from graphene to the analyte. Thus, the observed increase
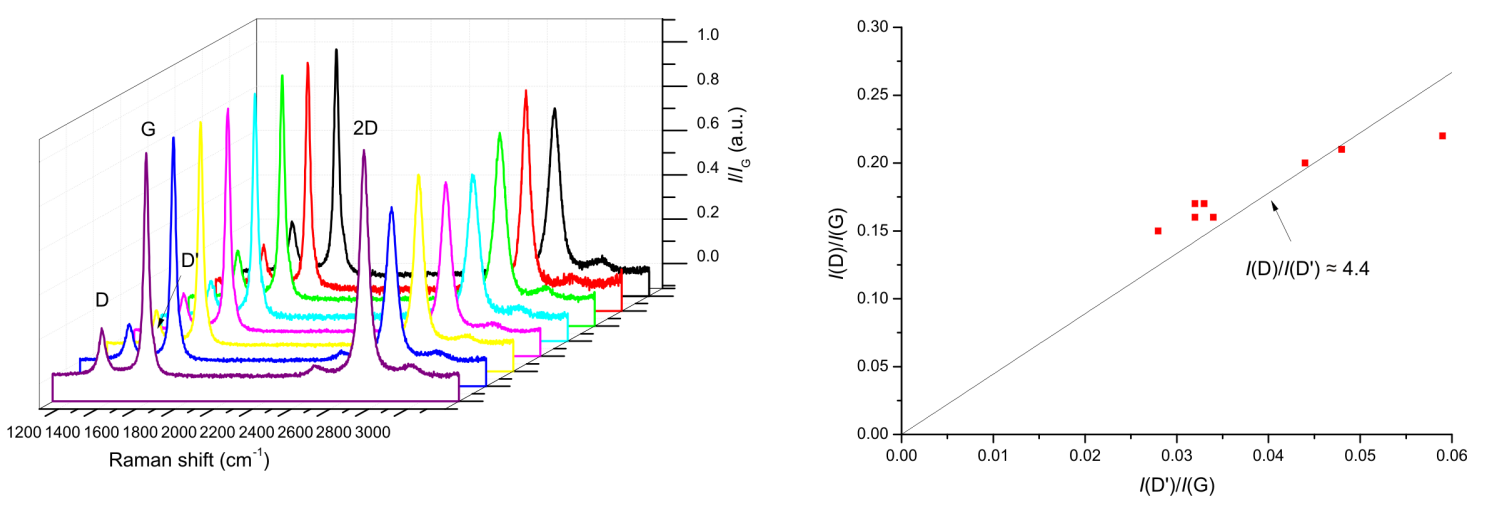

Figure 2: (Left): Raman spectra acquired in different points of the graphene film. (Right): Plot of $I(D) / /(G)$ vs $I\left(D^{\prime}\right) /((G)$ referred to the same spectra. 


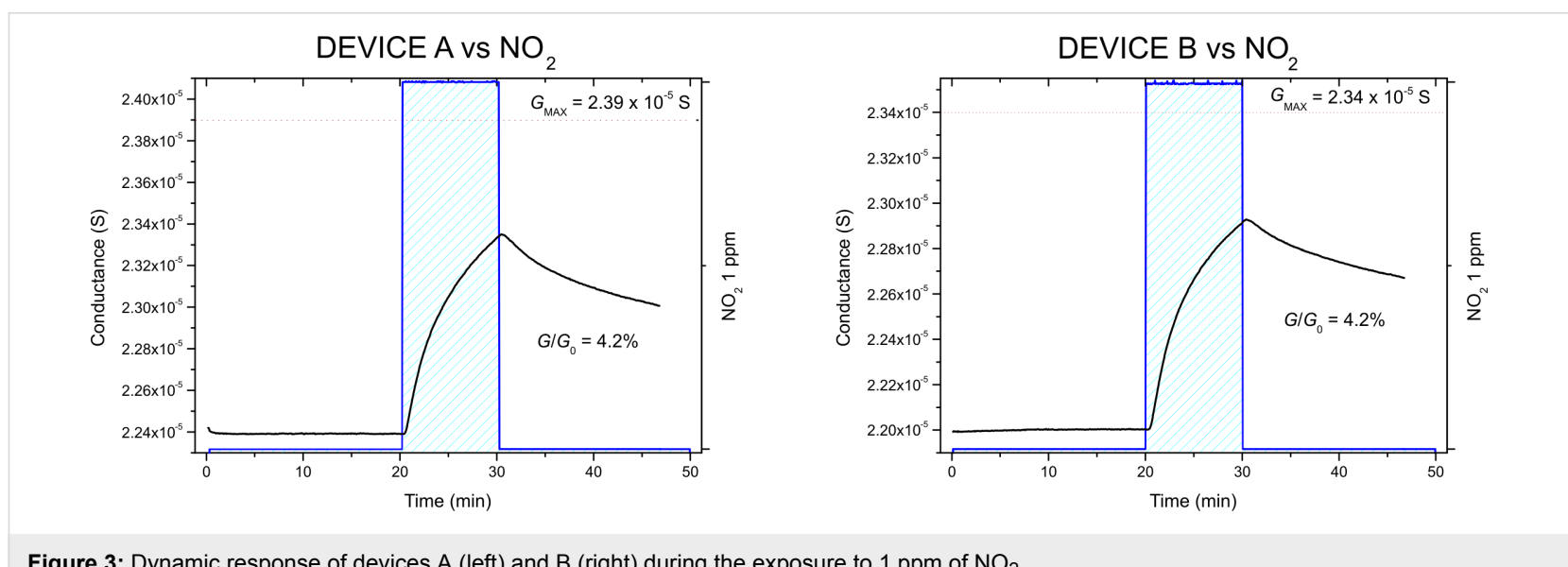

Figure 3: Dynamic response of devices $\mathrm{A}$ (left) and $\mathrm{B}$ (right) during the exposure to $1 \mathrm{ppm}$ of $\mathrm{NO}_{2}$.

in the device conductance is naturally expected because of the interaction of the molecule with a p-type material.

Subsequently, the devices have been exposed to $\mathrm{NH}_{3}$. Even in this case both chemiresistors exhibit a comparable percentage variation of the conductance, as well as similar kinetics (Figure 4). Because ammonia is an electron-donor analyte, the conductance show a decrease, further confirming the p-type nature of the synthesized graphene. At the end of the exposure to the analyte, the restoration of the initial conditions appears slow and incomplete.

Following the protocol described in the Experimental section, the devices have been finally exposed to $10 \mathrm{ppm}$ of $\mathrm{CO}$. The devices were completely unresponsive towards $\mathrm{CO}$ and therefore the measurements are not shown.

Apart from the direction of the conductance variation, the performances of the devices towards both $\mathrm{NO}_{2}$ and $\mathrm{NH}_{3}$, in terms of $\Delta G / G_{0}$ and response kinetics, appear almost comparable. In order to discriminate the differences in the graphene behaviour towards the two analytes at a deeper level, a reasonable description of the adsorption process should be provided. These mechanisms are conventionally well described by Arrhenius' law and the adsorption energies can be derived from the characteristic time of the desorption curve at different temperatures $[27,28]$. However, the desorption observed in the examined devices appears to be a result of different concurring phenomena, all of which comparably contribute to the exponential behaviour of the curve with a different characteristic time.

Hereinafter, an alternative point of view is proposed, based on the modification of the electronic properties of the material due to the analyte adsorption. Similarly to Arrhenius' concept of activation energy, this approach still includes the fundamental assumption of the validity of Maxwell-Boltzmann statistics.

The absolute number of analyte molecules approaching the devices has been firstly estimated, referring to the responses reported in Figure 3 and Figure 4. Within the approximation of an isotropic, quasi-stationary regime in the testing chamber and schematizing the chemiresistors surface as a rectangle of length
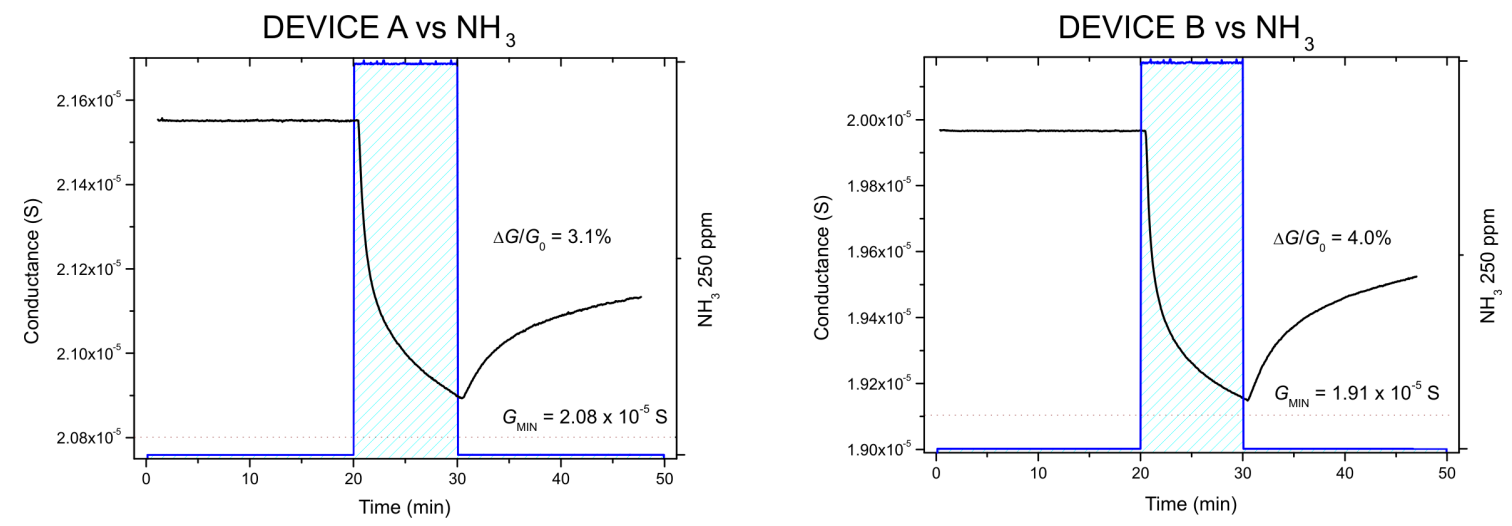

Figure 4: Dynamic response of devices $\mathrm{A}$ (left) and $\mathrm{B}$ (right) during the exposure to $250 \mathrm{ppm}$ of $\mathrm{NH}_{3}$. 
$l$ and width $w$, the total flow (500 sccm) has been converted into

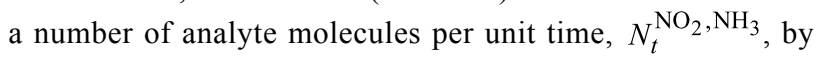
knowing the incoming concentrations ( $1 \mathrm{ppm}$ for $\mathrm{NO}_{2}$ and $250 \mathrm{ppm}$ for $\mathrm{NH}_{3}$ ). The total pressure in the testing chamber $\left(p_{\text {TOT }}=1 \mathrm{~atm}\right)$ has been taken into account. Furthermore, a uniform molecule density $d_{\mathrm{V}}=N_{t} / V_{\mathrm{c}}$ in the chamber $\left(V_{\mathrm{c}}=0.4 \mathrm{dm}^{3}\right)$ has been assumed:

$$
\begin{gathered}
N_{t}^{\mathrm{NO}_{2}, \mathrm{NH}_{3}}=d_{\mathrm{V}}^{2 / 3} \cdot l \cdot w, \\
N_{t}^{\mathrm{NO}_{2}}=9.8 \cdot 10^{4} \mathrm{~s}^{-1}, \\
N_{\text {tot }}^{\mathrm{NO}_{2}}=N_{t}^{\mathrm{NO}_{2}} \cdot 600 \mathrm{~s}=5.9 \cdot 10^{7},
\end{gathered}
$$

The effective number of colliding analyte molecules during the exposure in the time interval $\Delta t=600 \mathrm{~s}$ has finally been evaluated as:

$$
\begin{gathered}
N_{\text {tot }}^{\mathrm{NO}_{2}}=N_{t}^{\mathrm{NO}_{2}} \cdot 600=5.9 \cdot 10^{7} \text { molecules, } \\
N_{\text {tot }}^{\mathrm{NH}_{3}}=N_{t}^{\mathrm{NH}_{3}} \cdot 600 \mathrm{~s}=2.3 \cdot 10^{9}
\end{gathered}
$$

It is worth noting that the ration of these quantities for $\mathrm{NO}_{2}$ and $\mathrm{NH}_{3}$ is $250^{-2 / 3}$. This factor will be used later to normalize the number of adsorbed molecules to the same amount of incoming analyte.

The initial conductance value $G_{0}$ of the devices (lateral dimensions $l$ and $w$, thickness $t$ ) obeys Ohm's law:

$$
G_{0}=\sigma_{0} \frac{w t}{l}
$$

The conductivity can be expressed in terms of volumetric density and mobility of the charge carriers:

$$
\sigma=n_{\mathrm{V}} e \mu
$$

According to the mobility values reported in literature for CVD graphene (between $10^{2}$ and $10^{3} \mathrm{~cm}^{2} / \mathrm{V} \cdot \mathrm{s}$ ), in the calculations, a carrier mobility of $\mu \approx 1000 \mathrm{~cm}^{2} / \mathrm{V} \cdot \mathrm{s}$ has been assumed [29-31]. During the exposure, the number of carriers per unit surface has changed by the fraction $\Delta G / G_{0}$ in $10 \mathrm{~min}$. This quantity is linked to the number of adsorbed molecules via the virtual charge-transfer amount resulting from the interaction between graphene and analyte molecules, $\Delta q$. Hence, the effective number of analyte-induced charge carriers $N_{\mathrm{S}}$ onto the devices surface can be expressed as

$$
N_{\mathrm{S}}=\frac{\Delta G}{G_{0}} n_{\mathrm{V}}^{2 / 3} l \cdot w=N_{\mathrm{S}}^{\mathrm{ads}} \Delta q
$$

where $N_{\mathrm{S}}^{\text {ads }}$ is the number of analyte molecules adsorbed on the surface of the sensing film. A charge transfer of $-0.19 e$ for $\mathrm{NO}_{2}$ and $0.02 e$ for $\mathrm{NH}_{3}$ has been assumed, according to the theoretical results found by Zhang et al. on $\mathrm{NO}_{2}$ and $\mathrm{NH}_{3}$ adsorption on pristine graphene [32]. This choice has been made conforming to the results of the morphological characterizations, which attest a low defect density of the material and absence of substitutional impurities, so the material can be reasonably assumed as pristine.

The degree of adsorption, $\alpha$, is the ratio between the total number of adsorbed molecules and the total number of colliding analyte molecules during exposure:

$$
\alpha=\frac{N_{\mathrm{S}}^{\mathrm{ads}}}{N_{\text {tot }}} .
$$

For both examined devices a different behaviour can be distinguished for the two analytes, in particular $\alpha_{\mathrm{NO} 2} \approx 5 \alpha_{\mathrm{NH} 3}$ has been found, showing a predisposition of the sensing material towards $\mathrm{NO}_{2}$ detection (Table 1 and Table 2).

Finally, the characteristic energies related to the interaction between graphene and $\mathrm{NO}_{2} / \mathrm{NH}_{3}$ have been estimated. These parameters refer to the maximum number of molecules that can be adsorbed on the sensing strip. $N_{\mathrm{ads}}^{(\mathrm{max})}$ has been obtained by ex-

\begin{tabular}{|c|c|c|c|c|c|c|}
\hline & \multicolumn{6}{|c|}{$1 \mathrm{ppm} \mathrm{NO} 2$} \\
\hline & $\Delta G / G_{0}(\%)$ & $N_{\mathrm{S}}|e|$ & $N_{S}^{\text {ads }}$ & $\alpha$ & $N_{\text {ads }}^{(\max )}$ & $E_{\text {int }}(\mathrm{eV})$ \\
\hline device $A$ & 4.2 & $1.7 \cdot 10^{6}$ & $9.1 \cdot 10^{6}$ & 0.16 & $1.5 \cdot 10^{7}$ & $-0.413 \pm 0.001$ \\
\hline device $B$ & 4.2 & $1.6 \cdot 10^{6}$ & $8.0 \cdot 10^{6}$ & 0.14 & $1.3 \cdot 10^{7}$ & $-0.409 \pm 0.001$ \\
\hline
\end{tabular}
trapolating the maximum "asymptotic" increase/decrease of the conductance and converting it into the maximum amount of adsorbed molecules on the sensing strip by using the previous calculations. As far as $\mathrm{NH}_{3}$ is concerned, $N_{\text {ads }}^{(\max )}$ has been multiplied by the adjusting factor $250^{-2 / 3}$ in order to normalize the concentrations for both analytes.

Table 1: Summary of the relevant quantities descending from the interaction between graphene (devices $\mathrm{A}$ and $\mathrm{B}$ ) and $1 \mathrm{ppm}$ of $\mathrm{NO}_{2}$ during 10 min of exposure, calculated based on the responses reported in Figure 3. 
Table 2: Summary of the relevant quantities descending from the interaction between graphene (devices $\mathrm{A}$ and $\mathrm{B}$ ) and $250 \mathrm{ppm}$ of $\mathrm{NH}_{3}$ during 10 min of exposure, calculated based on the responses reported in Figure 4.

\begin{tabular}{|c|c|c|c|c|c|c|}
\hline & \multicolumn{6}{|c|}{250 ppm $\mathrm{NH}_{3}$} \\
\hline & $\Delta G / G_{0}(\%)$ & $N_{S}|e|$ & $N_{S}^{\text {ads }}$ & $\alpha$ & $N_{\text {ads }}^{(\max )}$ & $E_{\text {int }}(\mathrm{eV})$ \\
\hline device $A$ & 3.1 & $1.3 \cdot 10^{6}$ & $6.3 \cdot 10^{7}$ & 0.03 & $6.7 \cdot 10^{7}$ & $-0.358\left(\right.$ error $\left.<10^{-4}\right)$ \\
\hline device B & 4.0 & $1.5 \cdot 10^{6}$ & $7.6 \cdot 10^{7}$ & 0.03 & $8.3 \cdot 10^{7}$ & $-0.363\left(\right.$ error $\left.<10^{-4}\right)$ \\
\hline
\end{tabular}

Analogously to the conventional treatment of doped semiconductors, after having estimated the maximum number of adsorbed analyte molecules, they have been assimilated as punctual impurities in the crystal lattice. Herein the Maxwell-Boltzmann approximation for the statistical description of charge carriers can be justified by virtue of the semiclassical regime of the system, with low induced charge density, of the order of $10^{-2}$ with respect to that of the "undoped" material $\left(\approx 10^{12} \mathrm{~cm}^{-2}\right.$, which is an usual value for pristine graphene [33]) and a temperature sufficiently far from the quantum regime, $0 \mathrm{~K}$. Indeed, when $\exp \left(E / k_{\mathrm{B}} \mathrm{T}\right)>>1$, it is possible to write

$$
N_{\mathrm{ads}}^{(\max )} \approx \exp \left(-\frac{E_{\mathrm{int}}}{k_{\mathrm{B}} T}\right) \rightarrow E_{\mathrm{int}} \approx-k_{\mathrm{B}} T \ln N_{\mathrm{ads}}^{(\max )} .
$$

In particular, the estimated characteristic energies for $\mathrm{NO}_{2}$, both for devices A and B (Table 1), appear comparable to theoretical results regarding adsorption processes on graphene [31,34,35]. The calculated values also justify the slow and incomplete desorption of molecules, the thermal energy of which $\left(k_{\mathrm{B}} T \approx 25 \mathrm{meV}\right.$ ) is not sufficient to "escape" from the potential well associated to the adsorption.

The primary quantities $\left(\Delta G / G_{0}, N_{\mathrm{S}}, N_{\mathrm{S}}^{\text {ads }}, \alpha, N_{\mathrm{ads}}^{(\mathrm{max})}\right.$ and $\left.E_{\text {int }}\right)$ calculated for devices $\mathrm{A}$ and $\mathrm{B}$, for $\mathrm{NO}_{2}$ and $\mathrm{NH}_{3}$, are summarized in Table 1 and Table 2. As can be seen, these values are very similar for the two devices.

The presented quantitative model, assuming a static configuration of the system, is not fully representative of the complex charge carrier dynamics due to the adsorption of gas molecules on the graphene surface. Herein, additional mechanisms that affect the conductance behaviour, such as induced charge propagation within the layers of a single graphene grain, as well as the transfer through the edges of adjacent grains, are not taken into account. However, the utilized fabrication technique, which confers a remarkable control on the sensing film geometry, makes a simplifying schematization possible, so as to reasonably quantify the affinity between graphene and the different analytes at room temperature via the as-defined interaction energy $E_{\text {int }}$ and the degree of adsorption $\alpha$.
The drawback of slow and incomplete recovery in devices working at room temperature is well-known in the literature $[13,36,37]$. This disadvantage can be overcome by following different strategies, such as the introduction of a heater or a UV light source on board, able to restore the basic device conditions at the end of exposure to analyte [9-13]. Another possibility is to record the signal derivative of conductance [8] with a differentiator operational amplifier. In a CMOS-compatible process, all these devices could be directly fabricated on the same chip at micrometre-size. It is finally worth mentioning that, once proven the reliability of this process, it paves the way for the creation of a sensor array, able to provide selective responses towards the analytes. In addition, the possibility of miniaturizing such an array goes in the direction of creating a portable electronic nose.

\section{Conclusion}

We have shown the potential of a transfer-free deposition technique for the fabrication of graphene-based gas sensors by a process that is fully compatible with silicon electronics. The synthesis technique has proven to be highly replicable, as identical devices exhibit comparable performances. Notwithstanding a change of sign in the conductance variation, the chemiresistive devices have exhibited analogous responses towards $\mathrm{NO}_{2}$ and $\mathrm{NH}_{3}$, besides being totally insensitive to $\mathrm{CO}$. The similarity in the behaviour towards $\mathrm{NO}_{2}$ and $\mathrm{NH}_{3}$ has been studied in depth by evaluating the characteristic energies associated to the different analytes by following an unconventional approach, focusing on the modification of the electronic properties of the sensing material due to the analyte adsorption rather than the kinetics of the surface reactions. From this analysis a predisposition of transfer-free CVD graphene towards $\mathrm{NO}_{2}$ detection has clearly emerged. The remarkable control on the sensing film geometry, which is specific to the presented technique, enables a quantification of the interaction energy and the degree of adsorption of $\mathrm{NO}_{2}$ and $\mathrm{NH}_{3}$ at room temperature employing a simple descriptive model, the results of which are coherent with those reported in other theoretical works related to gas-adsorption processes on graphene.

The recovery time for these devices is typically extremely long, affecting the time stability of the base conductance as well as 
the sensing performances. The direct-growth approach for the synthesis of graphene opens a promising path towards the integration in electronic devices and the employment of additional technologies suitable for both speeding up the gas desorption and overcoming the abovementioned drawbacks.

\section{Experimental}

4" Si wafers coated by $90 \mathrm{~nm}$ thick thermal $\mathrm{SiO}_{2}$ layer have been employed for the synthesis. A thin film of Mo has been sputtered on top of it, starting from a pure (99.95\%) Mo target. The metal film thickness can be made as thin as $50 \mathrm{~nm}$ without any segregation at the graphene CVD temperature $\left(\approx 1000^{\circ} \mathrm{C}\right)$, because of the higher melting point of $\mathrm{Mo}\left(2623^{\circ} \mathrm{C}\right)$ compared to that of other conventional catalysts such as $\mathrm{Cu}\left(1085^{\circ} \mathrm{C}\right)$ or $\mathrm{Ni}\left(1455^{\circ} \mathrm{C}\right)$. Moreover, this allows a pre-patterning the film for the selective growth of graphene down to micrometre-size dimensions. A photo-lithographic process, combined with $\mathrm{SF}_{6}$ dry etching, has been used to shape the Mo in the desired form.

Graphene layers have then been grown on pre-patterned $\mathrm{Mo} / \mathrm{SiO}_{2} / \mathrm{Si}$ substrate by means of AIXTRON BlackMagic Pro equipment, setting the temperature at $1000{ }^{\circ} \mathrm{C}$, the pressure at 25 mbar and using $\mathrm{Ar} / \mathrm{H}_{2} / \mathrm{CH}_{4}$ as feedstock. At the end of the CVD growth, the Mo has been selectively etched away underneath graphene employing phosphoric acid. Due to anchoring at the sides of the patterned catalyst, the graphene layer sticks directly to the underlaying $\mathrm{SiO}_{2}$. $\mathrm{Cr} / \mathrm{Au}$ metal contacts have finally been patterned by a lift-off process to design a four-point probe structure. The final chemiresistive devices consist of a material strip $206 \mu \mathrm{m}$ long and $5 \mu \mathrm{m}$ wide, placed between two couples of metal electrodes (Figure 1).

Raman analyses have been performed at different points of the sensing strips by means of Renishaw InVia Reflex spectrometer, at $\lambda=514 \mathrm{~nm}$ and $20 \mathrm{~mW}$ incident laser power, in backscattering configuration.

The chemiresistors have been tested in a Gas Sensor Characterization System (GSCS, Kenosistec equipment) consisting of a stainless steel testing chamber $\left(V=0.4 \mathrm{dm}^{3}\right)$, placed in a thermostatic box. Precise amounts of analyte were let into the chamber via a system of programmable mass flow controllers (MKS) and electro-pneumatic valves. Relative humidity can be adjusted as required through a water bubbler placed in a thermostatic bath. The bias voltage is provided by TTi QL355T Precision Power Supply.

The following measurement protocol, schematized into three runs for a total duration of $50 \mathrm{~min}$, has been employed: (1) 20 min carrier gas flow (baseline), (2) 10 min exposure to the analytes at the chosen concentrations, (3) 20 min carrier gas flow (recovery). The measurements have been carried out in inert $\mathrm{N}_{2}$ environment, keeping the total flow at $500 \mathrm{sccm}$, at atmospheric pressure, relative humidity set at $50 \%, T=25{ }^{\circ} \mathrm{C}$. The devices have been kept at $1 \mathrm{~V}$ DC bias voltage. The sampling rate for the acquisition of the conductance values has been set to $0.25 \mathrm{~Hz}$. The dynamic response has been quantified as the percentage variation of the conductance:

$$
\frac{\Delta G}{G_{0}}(\%)=\frac{\left|G_{\mathrm{f}}-G_{0}\right|}{G_{0}} \cdot 100,
$$

where $G_{0}$ is the unperturbed conductance value and $G_{\mathrm{f}}$ is the conductance value at the end of the exposure.

\section{References}

1. Novoselov, K. S.; Fal'ko, V. I.; Colombo, L.; Gellert, P. R.; Schwab, M. G.; Kim, K. Nature 2012, 490, 192-200. doi:10.1038/nature11458

2. Varghese, S. S.; Lonkar, S.; Singh, K. K.; Swaminathan, S.; Abdala, A. Sens. Actuators, B 2015, 218, 160-183. doi:10.1016/j.snb.2015.04.062

3. Chen, G.; Paronyan, T. M.; Harutyunyan, A. R. Appl. Phys. Lett. 2012, 101, 053119. doi:10.1063/1.4742327

4. Ko, G.; Kim, H.-Y.; Ahn, J.; Park, Y.-M.; Lee, K.-Y.; Kim, J. Curr. Appl. Phys. 2010, 10, 1002-1004. doi:10.1016/j.cap.2009.12.024

5. Rumyantsev, S.; Liu, G.; Shur, M. S.; Potyrailo, R. A.; Balandin, A. A. Nano Lett. 2012, 12, 2294-2298. doi:10.1021/nl3001293

6. Yoon, H. J.; Jun, D. H.; Yang, J. H.; Zhou, Z.; Yang, S. S.; Cheng, M. M.-C. Sens. Actuators, B 2011, 157, 310-313. doi:10.1016/j.snb.2011.03.035

7. De Vito, S.; Castaldo, A.; Loffredo, F.; Massera, E.; Polichetti, T.; Nasti, I.; Vacca, P.; Quercia, L.; Di Francia, G. Sens. Actuators, B 2007, 124, 309-316. doi:10.1016/j.snb.2006.12.039

8. Ricciardella, F.; Massera, E.; Polichetti, T.; Miglietta, M. L.; Di Francia, G. Appl. Phys. Lett. 2014, 104, 183502. doi:10.1063/1.4875557

9. Charlier, J.-C.; Arnaud, L.; Avilov, I. V.; Delgado, M.; Demoisson, F.; Espinosa, E. H.; Ewels, C. P.; Felten, A.; Guillot, J.; lonescu, R.; Leghrib, R.; Llobet, E.; Mansour, A.; Migeon, H.-N.; Pireaux, J.-J.; Reniers, F.; Suarez-Martinez, I.; Watson, G. E.; Zanolli, Z. Nanotechnology 2009, 20, 375501. doi:10.1088/0957-4484/20/37/375501

10. Chen, R. J.; Franklin, N. R.; Kong, J.; Cao, J.; Tombler, T. W.; Zhang, Y.; Dai, H. Appl. Phys. Lett. 2001, 79, 2258-2260. doi:10.1063/1.1408274

11. Hyman, M. P.; Medlin, J. W. J. Phys. Chem. B 2005, 109, 6304-6310. doi:10.1021/jp045155y

12. Leghrib, R.; Llobet, E. Anal. Chim. Acta 2011, 708, 19-27. doi:10.1016/j.aca.2011.09.038

13. Schedin, F.; Geim, A. K.; Morozov, S. V.; Hill, E. W.; Blake, P.; Katsnelson, M. I.; Novoselov, K. S. Nat. Mater. 2007, 6, 652-655. doi:10.1038/nmat1967

14. Britnell, L.; Gorbachev, R. V.; Jalil, R.; Belle, B. D.; Schedin, F.; Mishchenko, A.; Georgiou, T.; Katsnelson, M. I.; Eaves, L.; Morozov, S. V.; Peres, N. M. R.; Leist, J.; Geim, A. K.; Novoselov, K. S.; Ponomarenko, L. A. Science 2012, 335, 947-950. doi:10.1126/science. 1218461 
15. Kim, K.; Choi, J.-Y.; Kim, T.; Cho, S.-H.; Chung, H.-J. Nature 2011, 479, 338-344. doi:10.1038/nature10680

16. Kim, K. S.; Zhao, Y.; Jang, H.; Lee, S. Y.; Kim, J. M.; Kim, K. S.; Ahn, J.-H.; Kim, P.; Choi, J.-Y.; Hong, B. H. Nature 2009, 457, 706-710. doi:10.1038/nature07719

17. Li, X.; Cai, W.; An, J.; Kim, S.; Nah, J.; Yang, D.; Piner, R.; Velamakanni, A.; Jung, I.; Tutuc, E.; Banerjee, S. K.; Colombo, L.; Ruoff, R. S. Science 2009, 324, 1312-1314.

doi:10.1126/science.1171245

18. Reina, A.; Jia, X.; Ho, J.; Nezich, D.; Son, H.; Bulovic, V.; Dresselhaus, M. S.; Kong, J. Nano Lett. 2009, 9, 3087. doi:10.1021/nl901829a

19. Sun, Z.; Yan, Z.; Beitler, E.; Zhu, Y.; Tour, J. M. Nature 2010, 468, 549-552. doi:10.1038/nature09579

20. Kwak, J.; Chu, J. H.; Choi, J.-K.; Park, S.-D.; Go, H.; Kim, S. Y.; Park, K.; Kim, S.-D.; Kim, Y.-W.; Yoon, E.; Kodambaka, S.; Kwon, S.-Y. Nat. Commun. 2012, 3, 645. doi:10.1038/ncomms 1650

21. Lukosius, M.; Wolff, A.; Schroeder, T.; Lupina, G. Graphene 2015 conference, Bilbao, Spain, March 10-13, 2015; 2015.

22. Chen, S.; Cai, W.; Chen, D.; Ren, Y.; Li, X.; Zhu, Y.; Kang, J.; Ruoff, R. S. New J. Phys. 2010, 12, 125011. doi:10.1088/1367-2630/12/12/125011

23. Bianco, G. V.; Losurdo, M.; Giangregorio, M. M.; Capezzuto, P.; Bruno, G. Phys. Chem. Chem. Phys. 2014, 16, 3632-3639. doi:10.1039/c3cp54451f

24. Vollebregt, S.; Alfano, B.; Ricciardella, F.; Giesbers, A. J. M.; Grachova, Y.; van Zeijl, H. W.; Polichetti, T.; Sarro, P. M. A transfer-free wafer-scale CVD graphene fabrication process for MEMS/NEMS sensors. In 2016 IEEE 29th International Conference on Micro Electro Mechanical Systems (MEMS), Shanghai, China, Jan 24-28, 2016; IEEE Publishing: Piscataway, NJ, U.S.A., 2016; pp 17-20. doi:10.1109/MEMSYS.2016.7421546

25. Eckmann, A.; Felten, A.; Mishchenko, A.; Britnell, L.; Krupke, R.; Novoselov, K. S.; Casiraghi, C. Nano Lett. 2012, 12, 3925-3930. doi:10.1021/nl300901a

26. Ulbricht, H.; Moos, G.; Hertel, T. Phys. Rev. B 2002, 66, 075404. doi:10.1103/PhysRevB.66.075404

27. Wolkenstein, T. Electronic Processes on Semiconductor Surfaces During Chemisorption; Springer: Berlin, Germany, 1991; p 460 doi:10.1007/978-1-4615-3656-7

28. Guérin, J.; Bendahan, M.; Aguir, K. Sens. Actuators, B 2008, 128 , 462-467. doi:10.1016/j.snb.2007.07.010

29. Reina, A.; Jia, X.; Ho, J.; Nezich, D.; Son, H.; Bulovic, V.; Dresselhaus, M. S.; Kong, J. Nano Lett. 2009, 9, 30-35. doi:10.1021/nl801827v

30. Song, H. S.; Li, S. L.; Miyazaki, H.; Sato, S.; Hayashi, K.; Yamada, A.; Yokoyama, N.; Tsukagoshi, K. Sci. Rep. 2012, 2, 337. doi:10.1038/srep00337

31. Wu, Y.; Yu, G.; Wang, H.; Wang, B.; Chen, Z.; Zhang, Y.; Wang, B.; Shi, X.; Xie, X.; Jinc, Z.; Liu, X. Carbon 2012, 50, 5226-5231. doi:10.1016/j.carbon.2012.07.007

32. Zhang, Y.-H.; Chen, Y.-B.; Zhou, K.-G.; Liu, C.-H.; Zeng, J.; Zhang, H.-L.; Peng, Y. Nanotechnology 2009, 20, 185504. doi:10.1088/0957-4484/20/18/185504

33. Novoselov, K. S.; Geim, A. K.; Morozov, S. V.; Jiang, D.; Zhang, Y.; Dubonos, S. V.; Grigorieva, I. V.; Firsov, A. A. Science 2004, 306, 666-669. doi:10.1126/science.1102896

34. Lin, X.; Ni, J.; Fang, C. J. Appl. Phys. 2013, 113, 034306. doi:10.1063/1.4776239
35. Sjövall, P.; So, S. K.; Kasemo, B.; Franchy, R.; Ho, W. Chem. Phys. Lett. 1990, 172, 125-130. doi:10.1016/0009-2614(90)87284-X

36. Yavari, F.; Koratkar, N. J. Phys. Chem. Lett. 2012, 3, 1746-1753. doi:10.1021/jz300358t

37. Yuan, W.; Shi, G. J. Mater. Chem. A 2013, 1, 10078-10091. doi:10.1039/c3ta11774j

\section{License and Terms}

This is an Open Access article under the terms of the Creative Commons Attribution License

(http://creativecommons.org/licenses/by/4.0), which permits unrestricted use, distribution, and reproduction in any medium, provided the original work is properly cited.

The license is subject to the Beilstein Journal of Nanotechnology terms and conditions:

(http://www.beilstein-journals.org/bjnano)

The definitive version of this article is the electronic one which can be found at: $\underline{\text { doi:10.3762/bjnano.8.102 }}$ 